Volume 1 Issue 2 (2017) Pages 97 - 104

Jurnal Obsesi : Jurnal Pendidikan Anak Usia Dini

DOI: $10.31004 /$ obsesi.v1i2.20

\title{
Pemberian Asi Eksklusif di Wilayah Kerja Puskesmas Tapung Perawatan Tahun 2015
}

\author{
Rizki Rahmawati Lestari ${ }^{\bowtie}$ \\ Fakultas Ilmu Kesehatan, Universitas Pahlawan Tuanku Tambusai
}

\begin{abstract}
Abstrak
Cakupan ASI Eksklusif di berbagai daerah di Indonesia masih jauh dari target Nasional. Penelitian ini bertujuan untuk mengetahui faktor-faktor yang berhubungan dengan pemberian ASI eksklusif di Wilayah Kerja Puskesmas Tapung Perawatan Kabupaten Kampar Propinsi Riau dengan desain cross sectional. Penelitian dilakukan pada tanggal 12-29 Juni 2015. Variabel dalam penelitian ini meliputi dukungan tenaga kesehatan, pengetahuan ibu, dukungan suami, pekerjaan ibu, pendidikan ibu, umur ibu dan umur kehamilan ibu saat melahirkan. Pengambilan sampel dengan cara systematic random sampling $(n=120)$. Data dianalisa menggunakan Uji Regresi Logistik. Hasil penelitian ini menunjukkan bahwa variabel yang berhubungan dengan pemberian ASI eksklusif adalah dukungan suami (POR:8,219 95\%CI=2,848-23,719), pekerjaan ibu (POR:5,188 95\%CI=1,264-21,301), dan pendidikan ibu (POR:3,785 95\%CI=1,110-12,904). Saran bagi pihak Puskesmas agar memberikan komunikasi, informasi, edukasi tentang ASI eksklusif kepada pasangan suami istri.
\end{abstract}

Kata kunci : ASI Eksklusif, dukungan suami, dukungan tenaga kesehatan

\begin{abstract}
Exclusive Breastfeeding coverage in various regions of Indonesia is still far from the National target. This study aims to determine the factors associated with exclusive breastfeeding in the Work Area Puskesmas Tapung Treatment District Kampar Riau Province with a crosssectional design. The research was conducted on June 12-29, 2015. The variables in this study include the support of health workers, mother's knowledge, husband support, mother's work, mother's education, mother's age and maternal age of the pregnancy. Sampling by systematic random sampling $(n=120)$. Data were analyzed using Logistic Regression Test. The results of this study indicate that the variables associated with exclusive breastfeeding are husband support (POR: 8,219 95\% CI = 2,848-23,719), maternal occupations (POR: 5.188 95\% CI = 1,264-21,301), and maternal education (POR: 3.785 95\% CI =1,110-12,904). Suggestions for the Puskesmas to provide communication, information, education about exclusive breastfeeding to married couples.
\end{abstract}

Keywords: Exclusive Breastfeeding, support of husband, support of health workers

@ Jurnal Obsesi Prodi PG-PAUD FIP UPTT 2017

$\triangle$ Corresponding author :

Address : Bangkinang, Kampar, Riau, Indonesia

ISSN 2356-1327 (Media Cetak)

Email : lrizkirahmawati48@gmail.com

ISSN 2549-8959 (Media Online) 


\section{PENDAHULUAN}

Berdasarkan Pasal 128 ayat (1) UU Kesehatan No 36 tahun 2009 bahwa setiap bayi berhak mendapatkan Air Susu Ibu (ASI) Eksklusif sejak dilahirkan selama 6 bulan kecuali atas indikasi medis (UU Kesehatan No. 36 tahun 2009). Pada Sidang Kesehatan Dunia ke-65, negara anggota - anggota WHO menetapkan target di tahun 2025 bahwa sekurangkurangnya $50 \%$ dari jumlah bayi di bawah usia 6 bulan diberi ASI Eksklusif. Saat ini persentase global ASI Eksklusif adalah $37 \%$ (WHO, 2014).

Menurut WHO, ASI Eksklusif merupakan ASI yang diberikan pada 6 bulan pertama bayi baru lahir tanpa adanya makanan pendamping lain, kecuali: vitamin, mineral/ obat dalam bentuk tetes/ sirup sampai bayi berusia 6 bulan. Pemberian ASI yang tidak optimal memberi dampak terhadap terjadinya kematian akibat infeksi neonatal $45 \%$, kematian akibat diare $30 \%$, dan akibat infeksi saluran pernafasan pada balita $18 \%$ (WHO, 2014).

Berdasarkan hasil data Riset Kesehatan Dasar (RISKESDAS) 2013, cakupan pemberian ASI di Indonesia hanya $30,2 \%$, sedangkan target nasional cakupan pemberian ASI Eksklusif sebesar 80\% (Kemenkes RI, 2013). Dari data cakupan pemberian ASI Eksklusif di Provinsi Riau, cakupan untuk bayi yang diberi ASI Eksklusif tahun 2013 sebesar 51,2\% (Dinas Kesehatan Provinsi Riau, 2014). Persentase bayi yang diberi ASI Eksklusif tahun 2013 di Kabupaten Kampar adalah 4.029 bayi dari 5.683 bayi (70,9\%), dan menurun di tahun 2014 berjumlah 4.615 bayi $(54,9 \%)$ dari 8.401 jumlah bayi keseluruhan (Dinas Kesehatan Kabupaten Kampar, 2014).

Berbagai penelitian yang telah dilakukan oleh para peneliti terdahulu, Sriningsih (2010) di BPM Siti Komariyatun di Desa Sukorejo Kec. Bojonegoro, variabel yang diteliti adalah pendidikan dan pengetahuan. Penelitian oleh Wirawati (2014)

di

RSKDIA Pertiwi Makasar, variabel yang diteliti adalah pendidikan dan pengetahuan dan dukungan suami. Penelitian

Rahmawati (2013) di wilayah kerja Puskesmas Bonto Cani Kab. Bone, yang diteliti adalah peranan tenaga kesehatan. Penelitian dilakukan di Wilayah Kerja Puskesmas XIII Koto Kampar I oleh Arini (2012), variabel yang diteliti adalah umur. Penelitian

yang dilakukan oleh Reni (2012) di RS Sayang bayi Jakarta, pernah melakukan penelitian dengan variabel pekerjaan ibu, namun berbeda pengelompokannya dengan penelitian ini. Perbedaannya adalah pada penelitian terdahulu, mengelompokkan pekerjaan menjadi bekerja dan tidak bekerja; sedangkan pada penelitian ini pekerjaan ibu dibagi menjadi formal (mempunyai keterikatan waktu kerja) dan non formal (waktu kerja tidak terikat). Sedangkan penelitian terdahulu dikatakan bekerja jika ibu yang bekerja di luar rumah, sehingga jauh dari bayi dengan lama waktu lebih atau sama dengan 6 jam.

Berdasarkan uraian di atas, peneliti melakukan penelitian terhadap 7 variabel yakni dukungan atau peranan tenaga kesehatan, pengetahuan ibu, dukungan suami, pekerjaan ibu, pendidikan ibu, umur ibu, umur kehamilan ibu saat melahirkan. Terlihat 2 dari 7 variabel yang penulis teliti bahwa variabel pekerjaan ibu dan umur kehamilan ibu saat melahirkan dengan pemberian ASI Eksklusif belum dilakukan. Informasi terkait dengan umur kehamilan merupakan teori yang dikemukakan oleh Roesli (2005) yakni bayi yang lahir prematur sangat lemah dan tidak mampu menghisap secara efektif sehingga produksi ASI lebih rendah dari pada bayi lahir normal. Penelitian ini belum pernah dilakukan di Wilayah Kerja Puskesmas Tapung Perawatan Kab. Kampar untuk Program Studi Magister Ilmu Kesehatan Masyarakat.

Berdasarkan data dari Puskesmas Tapung Perawatan, tahun 2013 yang mendapatkan ASI Eksklusif hanya 37,6\% dan meningkat di 2014 menjadi 46\%. Dari data tahun 2015 di salah satu Desa di Kecamatan Tapung yaitu Desa Petapahan Jaya, pada bulan Maret 2015 dari 32 bayi 
usia 0-6 bulan hanya 5 bayi yang mendapat ASI Eksklusif. Sebanyak 10 bayi tersebut tidak diberikan ASI Eksklusif disebabkan oleh dukungan suami yang kurang, 6 orang beralasan ibu bekerja sehingga ibu-ibu menghentikan pemberian ASI Eksklusif, dan 4 orang disebabkan oleh masih rendahnya pendidikan ibu, dimana kebanyakan pendidikan terakhir ibu adalah SD dan SMP.

$$
\text { Berdasarkan laporan dari }
$$

Puskesmas Tapung Perawatan 2013 dan 2014, cakupan ASI Eksklusif masih jauh dari target. Maka peneliti berminat mengambil judul tentang "Pemberian ASI Eksklusif di Wilayah Kerja Puskesmas Tapung Perawatan Tahun 2015".

Rumusan masalah dalam penelitian ini adalah "Bagaimanakah Pemberian ASI Eksklusif di Wilayah Kerja Puskesmas Tapung Perawatan Tahun 2015?”.

\section{METODOLOGI PENELITIAN}

Penelitian ini kuantitatif analitik dengan jenis desain cross sectional. Pengumpulan data ini dilakukan pada tanggal 12-29 Juni 2015. Populasi dalam penelitian ini adalah ibu-ibu yang mempunyai bayi usia 7-11 bula di Wilayah Kerja Puskesmas Tapung Perawatan, dengan sampel 120 responden. Pengumpulan data dilakukan dengan menggunakan kuesioner, analisis data menggunakan analisis univariat, bivariat dan multivariat.

\section{HASIL DAN PEMBAHASAN}

Hasil analisis univariat didapatkan Ibu yang tergolong tidak menyusui secara

\begin{tabular}{|c|c|c|c|c|c|c|c|}
\hline \multirow[b]{3}{*}{ Variabel } & \multicolumn{5}{|c|}{ ASI Eksklusif } & \multirow{3}{*}{$\begin{array}{c}P \\
\text { Value }\end{array}$} & \multirow{3}{*}{$\begin{array}{c}\text { POR } \\
(95 \% \text { CI })\end{array}$} \\
\hline & \multicolumn{2}{|c|}{ Non Eksklusif } & \multicolumn{2}{|c|}{ Eksklusif } & Total & & \\
\hline & $\mathbf{n}$ & $\%$ & $\mathbf{n}$ & $\%$ & $(\%)$ & & \\
\hline Dukungan nakes & & & & & & & \\
\hline Kurang & 45 & 88,2 & 6 & 11,8 & $51(100)$ & 0,000 & $11,669(4,381-31,069)$ \\
\hline Baik & 27 & 39,1 & 42 & 60,9 & $69(100)$ & & \\
\hline Total & 72 & 60 & 48 & 40 & $120(100)$ & & \\
\hline
\end{tabular}

eksklusif yaitu 60\% (72 orang), dukungan nakes yang baik sebanyak 57,5\% (69 orang), ibu yang berpengetahuan kurang yaitu 53,3\% (64 orang), suami yang kurang mendukung sebanyak 51,7\% (62 orang), ibu yang bekerja secara formal sebanyak $54,2 \%$ (65 orang), ibu yang berpendidikan rendah sebanyak 70,8\% (85 orang), ibu yang berumur 20-35 tahun sebanyak 53,3\% (64 orang), dan ibu dengan umur kehamilan prematur saat melahirkan sebanyak 53,3\% (64 orang).

Hasil analisis bivariat dari 7 (tujuh) variabel independen, semua berhubungan signifikan dengan kejadian pemberian ASI Eksklusif yaitu: dukungan tenaga kesehatan, pengetahuan, dukungan suami, pekerjaan, pendidikan, umur dan umur kehamilan saat melahirkan (Lihat tabel 1).

Hasil analisis multivariat dapatt disimpulkan bahwa variabel yang berhubungan secara signifikan dengan pemberian ASI Eksklusif adalah dukungan suami, pekerjaan ibu dan pendidikan ibu. Dan variabel yang confounding terdiri dari: pengetahuan ibu confounding terhadap dukungan suami, dan umur ibu confounding terhadap dukungan tenaga kesehatan, serta dukungan tenaga kesehatan confounding terhadap pengetahuan ibu, dukungan suami, pekerjaan ibu, pendidikan ibu dan umur ibu. Sedangkan variabel yang tidak berhubungan dengan pemberian ASI Eksklusif adalah umur ibu dan umur kehamilan ibu saat melahirkan (Lihat tabel 2). 
100 | Pemberian Asi Eksklusif di Wilayah Kerja Puskesmas Tapung

\begin{tabular}{|c|c|c|c|c|c|c|c|}
\hline \multirow{3}{*}{ Variabel } & \multicolumn{5}{|c|}{ ASI Eksklusif } & \multirow{3}{*}{$\begin{array}{c}P \\
\text { Value }\end{array}$} & \multirow{3}{*}{$\begin{array}{c}\text { POR } \\
(95 \% \mathrm{CI})\end{array}$} \\
\hline & \multicolumn{2}{|c|}{ Non Eksklusif } & \multicolumn{2}{|c|}{ Eksklusif } & Total & & \\
\hline & $\mathbf{n}$ & $\%$ & $\mathbf{n}$ & $\%$ & $(\%)$ & & \\
\hline \multicolumn{8}{|l|}{ Pengetahuan ibu } \\
\hline Kurang & 49 & 76,6 & 15 & 23,4 & $64(100$ & 0,000 & $4,687(2,136-10,287)$ \\
\hline \multirow[t]{2}{*}{ Baik } & 23 & 41,1 & 33 & 58,9 & $56(100)$ & & \\
\hline & 72 & 60 & 48 & 40 & $120(100)$ & & \\
\hline \multicolumn{8}{|l|}{ Dukungan suami } \\
\hline Kurang & 52 & 83,9 & 10 & 16,1 & $62(100)$ & 0,000 & 9,880 \\
\hline Baik & 20 & 34,5 & 38 & 65,5 & $58(100)$ & & $(4,153-23,505)$ \\
\hline Total & 72 & 60 & 48 & 40 & $120(100)$ & & \\
\hline \multicolumn{8}{|l|}{ Pekerjaan ibu } \\
\hline Formal & 54 & 83,1 & 11 & 16,9 & $65(100)$ & 0,000 & $10,091(4,275-23,819)$ \\
\hline Non Formal & 18 & 32,7 & 37 & 67,3 & $55(100)$ & & \\
\hline Total & 72 & 60 & 48 & 40 & $120(100)$ & & \\
\hline \multicolumn{8}{|l|}{ Pendidikan ibu } \\
\hline Pendidikan Rendah & 56 & 65,9 & 29 & 34,1 & $85(100)$ & 0,040 & $2,293(1,028-5,114)$ \\
\hline Pendidikan Tinggi & 16 & 45,7 & 19 & 54,3 & $35(100)$ & & \\
\hline Total & 72 & 60 & 48 & 40 & $120(100)$ & & \\
\hline \multicolumn{8}{|l|}{ Umur ibu } \\
\hline $\begin{array}{l}\text { Usia }<20 \text { tahun dan } \\
>35 \text { tahun }\end{array}$ & 45 & 80,4 & 11 & 19,6 & $56(100)$ & 0,000 & $5,606(2,457-12,793)$ \\
\hline Usia 20-35 tahun & 27 & 42,2 & 37 & 57,8 & $64(100)$ & & \\
\hline Total & 72 & 60 & 48 & 40 & $120(100)$ & & \\
\hline \multicolumn{8}{|c|}{$\begin{array}{l}\text { Umur kehamilan ibu saat } \\
\text { melahirkan }\end{array}$} \\
\hline Prematur & 50 & 78,1 & 14 & 21,9 & $64(100)$ & 0,000 & $5,519(2,482-12,275)$ \\
\hline Normal & 22 & 39,3 & 34 & 60,7 & $56(100)$ & & \\
\hline Total & 72 & 60 & 48 & 40 & $120(100)$ & & \\
\hline
\end{tabular}

Tabel 2

PEMODELAN MULTIVARIAT VI (PEMODELAN AKHIR)

\begin{tabular}{|c|c|c|c|c|c|}
\hline \multirow[t]{2}{*}{ No } & \multirow[t]{2}{*}{ Variabel } & \multirow[t]{2}{*}{ Pvalue } & \multirow[t]{2}{*}{ POR } & \multicolumn{2}{|c|}{$(95 \% \mathrm{CI})$} \\
\hline & & & & Lower & Upper \\
\hline 1 & Dukungan nakes & 0,222 & 3,931 & 0,438 & 35,295 \\
\hline 2 & Pengetahuan ibu & 0,313 & 1,822 & 0.568 & 5,847 \\
\hline 3 & Dukungan suami & 0,000 & 8,219 & 2,848 & 23,719 \\
\hline 4 & Pekerjaan ibu & 0,022 & 5,188 & 1,264 & 21,301 \\
\hline 5 & Pendidikan ibu & 0,033 & 3,785 & 1,110 & 12,904 \\
\hline 6 & Umur ibu & 0,792 & 0,767 & 0,106 & 5,528 \\
\hline
\end{tabular}


PEMBAHASAN

Faktor-Faktor yang Berhubungan dengan Pemberian ASI Eksklusif

Hubungan Dukungan Suami dengan Pemberian ASI Eksklusif

Dalam penelitian ini ditemukan bahwa ibu dengan dukungan suami yang kurang dapat

menyebabkan tidak diberikannya ASI Eksklusif pada bayi. Dalam penelitian ini ditemukan variabel counfounding terhadap dukungan suami yaitu variabel pengetahuan ibu. Pengetahuan ibu berhubungan secara statistik dengan pemberian ASI Eksklusif dan dengan dukungan suami. Pengetahuan ibu yang kurang dapat menyebabkan bayi tidak disusui secara eksklusif. Jadi untuk menghindari tidak diberikannya ASI Eksklusif, maka dukungan suami harus ditingkatkan. Ibu dengan dukungan suami yang kurang mempunyai risiko 8,2 kali untuk tidak menyusui secara eksklusif.

Diharapkan kepada pihak

Puskesmas agar memberikan informasi kepada suami ibu melalui pembentukan Program suami siaga atau kelompok Ayah ASI, dan penyuluhan melalui program KIE agar mau menemani istrinya pada saat pemeriksaan kehamilan hingga persalinan supaya para suami mempunyai pengetahuan yang baik dan benar mengenai pentingnya pemberian ASI Eksklusif bagi bayi.

Hubungan Pekerjaan Ibu dengan Pemberian ASI Eksklusif

Dalam penelitian ini ditemukan bahwa ibu yang bekerja di sektor formal menyebabkan ibu tidak menyusui bayinya secara eksklusif. Dalam penelitian ini ditemukan satu variabel counfounding terhadap pekerjaan ibu yaitu variabel dukungan tenaga kesehatan. Dukungan nakes berhubungan secara statistik dengan pemberian ASI Eksklusif dan dengan pekerjaan ibu. Dukungan nakes yang kurang dapat menyebabkan bayi tidak disusui secara eksklusif. Ibu dengan pekerjaan formal mempunyai risiko lebih besar untuk tidak menyusui secara eksklusif.
Sebaiknya ibu yang bekerja di sektor formal diberikan penyuluhan oleh tenaga kesehatan tentang bagaimana memberikan susu perahan pada bayinya. Ibu harus mempunyai pengetahuan mulai dari cara memerah ASI, penyimpanan sampai bagaimana cara memberikan ASI perahan pada bayi. Didapatkan hasil bahwa ibu dengan pekerja formal berisiko 5,2 kali untuk tidak menyusui secara eksklusif.

\section{Hubungan Pendidikan Ibu dengan Pemberian ASI Eksklusif}

Dalam penelitian ini ditemukan bahwa pendidikan ibu yang rendah dapat menyebabkan tidak diberikannya ASI Eksklusif pada bayi. Dalam penelitian ini ditemukan satu variabel counfounding terhadap pendidikan ibu yaitu variabel dukungan nakes. Dukungan tenaga kesehatan berhubungan secara statistik dengan pemberian ASI Eksklusif dan dengan pendidikan ibu. Dukungan tenaga kesehatan yang kurang dapat menyebabkan bayi tidak disusui secara eksklusif. Jadi untuk menghindari tidak diberikannya ASI Eksklusif, tenaga kesehatan harus memberikan penyuluhan kepada ibu-ibu khususnya ibu dengan pendidikan rendah. Ibu dengan pendidikan rendah mempunyai risiko 3,8 kali untuk tidak menyusui secara eksklusif.

Secara keseluruhan, diketahui bahwa confounding faktor yang paling dominan dalam penelitian ini adalah dukungan tenaga kesehatan. Dari hasil penilitian ditemukan bahwa dukungan tenaga kesehatan merupakan confounding dari 5 variabel lainnya yaitu: dukungan suami, pengetahuan, pekerjaan, pendidikan dan umur. Dukungan petugas kesehatan mempunyai peranan sangat penting dalam menunjang pemberian ASI. Peran petugas kesehatan dapat membantu ibu untuk memberikan ASI dengan baik dan mencegah masalah-masalah yang terjadi.

Faktor-faktor yang Tidak Berhubungan dengan Pemberian ASI Eksklusif Hubungan Umur Ibu dengan Pemberian ASI Eksklusif

Dalam penelitian ini variabel umur tidak signifikan dengan pemberian ASI 
Eksklusif. Artinya, baik ibu dengan usia 20-35 tahun ataupun $<20$ dan $>35$ tahun tidak mempengaruhi pemberian ASI Eksklusif. Untuk penelitian selanjutnya, sebaiknya untuk variabel independen umur jangan digunakan skala kategorikal tetapi skala continuous.

\section{Hubungan Umur Kehamilan Ibu saat Melahirkan}

Umur kehamilan ibu saat melahirkan tidak berhubungan secara signifikan, artinya baik kelahiran prematur ataupun normal tidak mempengaruhi pemberian ASI Eksklusif. Ini mungkin terjadi karena karena ada kesalahan dalam mengkategorikan umur kehamilan saat melahirkan. Untuk mengatasi masalah ini dilakukan tinjauan kepustakaan dengan melihat kategori yang mana yang menunjukkan hubungan signifikan atau menggunakan skala continuous.

\section{KESIMPULAN}

Dari hasil analisis multivariat,
variabel yang berhubungan secara
signifikan adalah dukungan suami,
pekerjaan ibu dan pendidikan ibu. Dan
variabel yang tidak berhubungan adalah
umur ibu dan umur kehamilan ibu saat
melahirkan. Sedangkan variabel yang
confounding terdiri dari: pengetahuan ibu
confounding terhadap dukungan suami,
dan umur ibu confounding terhadap
dukungan tenaga kesehatan, serta
dukungan tenaga kesehatan confounding
terhadap pengetahuan ibu, dukungan
suami, pekerjaan ibu, pendidikan ibu dan
umuribu.

\section{SARAN}

Memberikan komunikasi, informasi dan edukasi (KIE) mengenai pengetahuan tentang ASI Eksklusif oleh pihak Puskesmas mengacu pada 10 langkah menuju keberhasilan menyusui kepada para ibu dan keluarga, khususnya kepada para suami.

Setiap tempat kerja yang mempunyai pekerja wanita hendaknya menyediakan ruangan untuk memerah ASI yang memadai, memberikan izin dan waktu untuk memerah ASI, dan cuti hamil yang fleksibel, sehingga tidak ada alasan lagi bagi ibu untuk tidak menyusui bayinya pada usia 0-6 bulan secara eksklusif.

Bagi ibu-ibu yang menitipkan bayinya kepada anak-anak yang putus sekolah yang ada di sekitar rumahnya, sebaiknya anak-anak tersebut diberikan pendidikan oleh tenaga kesehatan tentang cara merawat bayi. Hal tersebut akan bermanfaat bagi bayi dan juga memberi peluang kepada anak putus sekolah tersebut sehingga mereka bisa bekerja di tempat penitipan anak, dimana sebelumnya para ibu telah membekali bayinya ASI, sehingga bayi tetap mendapatkan ASI secara Eksklusif.

Karena terlihat perbedaan angka proporsi ASI Eksklusif di Wilayah Kerja Puskesmas Tapung Perawatan dari tahun 2013, 2014 dan 2015 yaitu berturut-turut: $37,6 \%, 46 \%$ dan 40\%, maka disarankan untuk melakukan sensus pemberian ASI Eksklusif untuk dijadikan faktor koreksi terhadap proporsi yang dilaporkan oleh tenaga kesehatan maupun oleh para peneliti.

Disarankan kepada Pihak Puskesmas Tapung Perawatan bekerja sama dengan instansi/lembaga terkait untuk membuat pojok ASI, yang sekarang lebih dikenal dengan Klinik Laktasi di Instansi Pemerintahan dan di tempattempat umum agar pemberian ASI secara Eksklusif dapat terlaksana. Diharapkan juga agar program ASI Eksklusif bisa menjadi salah satu program priotas untuk KIA/KB di Puskesmas Tapung Perawatan.

Disarankan kepada pihak puskesmas untuk mengupayakan terbentuknya Kelompok Peduli ASI (KPASI), dan merujuk ibu kepada kelompok tersebut ketika pulang dari Rumah Sakit atau sarana pelayanan kesehatan lainnya.

Disarankan kepada peneliti selanjutnya untuk meneliti variabel dukungan pemerintah daerah (Pemda) terhadap pemberian ASI Eksklusif.

\section{UCAPAN TERIMAKASIH}

Ucapan terimakasih ditujukan kepada dr H. Zainal Abidin, MPH selaku Ketua STIKes dan sebagai pembimbing II, 
serta DR. Buchari Lapau, dr, MPH selaku Ketua Prodi Magister IKM STIKes Hang Tuah Pekanbaru. DR. Aslis Wirda Hayati, SP, M. Si selaku pembimbing II serta Jasrida Yunita, SKM, M. Kes dan Dedy Sambudi, SKM, M. Kes selaku penguji. dr. Zulhendra Das'at selaku Kepala UPTD Puskesmas Tapung Perawatan tempat penelitian ini dilakukan. Peneliti juga mengucapkan terimakasih kepada responden yang telah bersedia meluangkan waktu sehingga peneliti dapat melaksanakan penelitian ini sampai selesai.

\section{DAFTAR PUSTAKA}

Ambarwati, E. R dan Diah, W. (2009). Asuhan Kebidanan Nifas. Cetakan 3. Jogjakarta: MITRA CENDIKIA Press.

Arini. (2012). Hubungan Umur dan Peranan Nakes dengan Pemberian ASI Eksklusif di Puskesmas XIII Koto Kampar I Tahun 2012. Tidak Dipublikasikan. Skripsi STIKes Tuanku Tambusai Riau.

Ariwati.(2014). Hubungan Dukungan Bidan tentang Pemberian ASI Eksklusif dengan Perilaku Pemberian ASI Eksklusif di Wilayah Kerja Puskesmas Ambarawa Kabupaten Semarang. Jurnal Kesehatan (1-15).

Atabik, A. (2013). Faktor Ibu yang Berhubungan dengan Praktik Pemberian ASI Eksklusif di Wilayah Kerja Puskesmas Pamotan. Skripsi Jurusan Ilmu Kesehatan Masyarakat Universitas Negeri Semarang.

Departemen Kesehatan, RI. (2001). Standar Pelayanan Kebidanan.

Dinas Kesehatan. (2013). Laporan Cakupan ASI Eksklusif Kabupaten Kampar.

Elsera. (2013). Faktor-faktor yang Berhubungan dengan Pemberian ASI Eksklusif di Wilayah kerja Puskesmas Ngaliyan Semarang.
Jurnal Ilmu Keperawatan STIKes Telogorejo Semarang (1-14).

Hargi, J, P. (2013). Hubungan Dukungan Suami dengan Sikap Ibu dalam Pemberian ASI Eksklusif di Wilayah Kerja Puskesmas Arjasa Kab. Jember. Jurnal Ilmu Keperawatan Universitas Jember.

Hastono, S, P. (2007). Analisis Data Kesehatan. Fakultas Kesehatan Masyarakat Universitas Indonesia.

Ida. (2011). Faktor-faktor yang Berhubungan dengan Pemberian ASI Eksklusif 6 Bulan di Wilayah Kerja Puskesmas Kemiri Muka Kota Depok. Tesis Fakultas Kesehatan Masyarakat Depok.

Joni, J. (2015). Hubungan Pola Asuh Orang Tua Terhadap Perkembangan Bahasa Anak Prasekolah (3-5 Tahun) Di PAUD Al-Hasanah Tahun 2014. Jurnal Obsesi, 1(1), 42-48.

Jusnawati. (2010). Ketersediaan Waktu Dalam Menyusui, (http://jusnawati.com /2014/003/ ketersediaan waktu menyusui//.html. diakses 3 April 2015).

Kantor Kecamatan Tapung. (2014). Peta Kecamatan Tapung.

Kementrian Kesehatan RI. (2013). Data Riskesdas 2013.

Kementrian Pemberdayaan Perempuan. (2010). Pedoman Peningkatan Penerapan 10 Langkah Menuju Keberhasilan Menyusui yang Responsif Gender Bagi Pusat dan Daerah. Kementrian Pemberdayaan Perempuan dan Perlindungan Anak Republik Indonesia.

Lapau, B. (2013). Metode Penelitian Kesehatan Metode Ilmiah Penulisan Skripsi, Tesis, dan Disertasi. Jakarta: Yayasan Obor Indonesia.

Lestari, D. (2013). Hubungan Tingkat Pengetahuan Ibu tentang ASI dan 
104 | Pemberian Asi Eksklusif di Wilayah Kerja Puskesmas Tapung

Pekerjaan Ibu dengan Pemberian ASI Eksklusif di Kelurahan Fajar Bulan. Jurnal Fakultas Kedokteran Universitas Lampung 88-99.

Lwanga, S.K. and S. Lemoshow. (1997). Sample Size Determinantion In Health Studies A Practical Manual. WHO Geneva.

Mamonto, T. (2015). Faktor yang Berhubungan dengan Pemberian ASI Eksklusif pada Bayi di Wilayah Kerja Puskesmas Koto Bangun Kec. Kota Mobagu Timur Kota Mobagu. Jurnal Ilmu Kesehatan Masyarakat Program Pascasarjana Universitas Sam Ratulangi (56-66).

Notoatmodjo. (2002). Metodologi Penelitian Kesehatan. Edisi Revisi. Jakarta: Rineka Cipta.

Nurmalina, N. (2015). Pantang Larang dalam Masyarakat Kampar dan Relevansinya dengan Pendidikan Karakter. Jurnal Obsesi, 1(1), 2735.

Permenkes no. 75 Tahun 2014. (2014). Konsep Dasar Puskesmas.

Proverawati, A dan Siti, A. (2009). Gizi Untuk Kebidanan. Yogyakarta: Nuha Medika.

Puskesmas Tapung Perawatan. (2013). Cakupan ASI Eksklusif di Puskesmas Tapung.

Puskesmas Tapung Perawatan. (2014). Peta Wilayah Kerja Puskesmas Tapung Perawatan.

Rahayu. (2010). Umur Sebagai Indikator Kedewasaan Dalam Pengambilan Keputusan, (http : //rahayu/2014/001/umur sebagai indikator kedewasaan dalam pengambilan keputusan_//.html. diakses 23 April 2015).

Rahmawati. (2013). Hubungan antara Karakteristik Ibu, Dukungan Nakes dan Dukungan Keluarga dengan Pemberian ASI Eksklusif di Wilayah Kerja Puskesmas Bonto
Cani Kab. Bone. Jurnal Program Studi Gizi Fakultas Ilmu Kesehatan Masyarakat. Universitas Hasanuddin Makassar (1-16).

Ransum. (2013). Hubungan Sikap Ibu, Pendidikan dan Dukungan Petugas Kesehatan dengan Pemberian ASI Eksklusif pada Bayi Umur 6-11 Bulan di Puskesmas Antang Perumnas Kota Makassar. Jurnal Ilmu Gizi Fakultas Kesehatan Masyarakat Universitas Hasanuddin (1-11).

Reni. (2012). Faktor yang Mempengaruhi Pemberian ASI Eksklusif pada Bayi Cukup Bulan yang Dilakukan Inisiasi Menyusui Dini (IMD) di Salah Satu RS Sayang Bayi di Jakarta. Tesis Fakultas Kedokteran Universitas Indonesia.

Roesli, U. (2005). Mengenal ASI Eksklusif. Cetakan III. Jakarta: Trubos Agriwidya.

Sriningsih. (2010). Hubungan Antara Faktor Budaya, Pendidikan dan Pengetahuan dengan Pemberian ASI Eksklusif. Jurnal Kesehatan Masyarakat 6(2) 100-106.

Undang-undang RI No. 36 Tahun 2009 Tentang Kesehatan. (2009). Jakarta.

WHO. (2014). Target dan Pencapaian ASI Eksklusif di Dunia, (http : //WHO/2014/target dan pencapaian ASI ekslusif//.html. diakses 19 April 2015).

Wirawati. (2014). Pengaruh faktor Sosial Ibu Terhadap Keberhasilan Menyusui pada Dua Bulan Pertama. Jurnal Kedokteran Brawijaya, Vol. 28, No. 2 (146151). 